\title{
Thermo-mechanical and optical properties of calcium aluminosilicate glasses doped with $\mathrm{Er}^{3+}$ and $\mathrm{Yb}^{3+}$
}

\author{
J.A. Sampaio $^{\text {a }}$, T. Catunda ${ }^{\text {a }}$, A.A. Coelho ${ }^{\text {b }}$, S. Gama ${ }^{\text {b }, ~ A . C . ~ B e n t o ~}{ }^{\text {c }}$, \\ L.C.M. Miranda ${ }^{\mathrm{c}}$, M.L. Baesso ${ }^{\mathrm{c}, *}$ \\ ${ }^{a}$ Instituto de Física de São Carlos, Universidade de São Paulo, 13560-250 São Carlos, SP, Brazil \\ ${ }^{\mathrm{b}}$ Instituto de Física Gleb Wataghin, Universidade Estadual de Campinas, 13083-970 Campinas, SP, Brazil

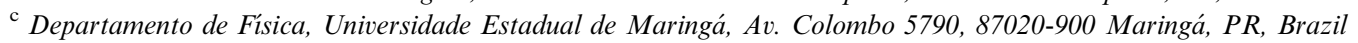

\begin{abstract}
In this work a series of $\mathrm{Er}_{2} \mathrm{O}_{3}$ and $\mathrm{Yb}_{2} \mathrm{O}_{3}$ doped and $\mathrm{Er}_{2} \mathrm{O}_{3}-\mathrm{Yb}_{2} \mathrm{O}_{3}$ co-doped low silica calcium aluminosilicate glasses have been melted at $1470^{\circ} \mathrm{C}$ under vacuum conditions. Measurements of optical absorption coefficient, mass density, refractive index, Vickers micro-hardness, glass transformation temperature $\left(T_{\mathrm{g}}\right)$ and crystallization temperature $\left(T_{\mathrm{x}}\right)$ have been carried out. The results showed that these glasses dissolved $\sim 1.5 \mathrm{~mol} \% \mathrm{Er}_{2} \mathrm{O}_{3}$ and $\sim 1.1 \mathrm{~mol}^{1} \% \mathrm{Yb}_{2} \mathrm{O}_{3}$ in their structure without devitrification and also that only small changes $(\sim 10 \%)$ have been measured in their thermal, mechanical and optical properties. (c) 2000 Elsevier Science B.V. All rights reserved.
\end{abstract}

\section{Introduction}

Recently, the emission of light at $2.8 \mu \mathrm{m}$ from an oxide glass has been successfully observed [1]. The glass was low silica content calcium aluminosilicate glasses doped with erbium and ytterbium. The idea behind the use of rare earth (RE) co-doping is to take advantage of the fact that $\mathrm{Yb}^{3+}$ acts as sensitizer for $\mathrm{Er}^{3+}$, a mechanism which has been known for a long time [2]. Light sources in the $2.8 \mu \mathrm{m}$ region are of particular interest for medical applications due to the water absorption in this spectral region [3], as well as for communications and chemical sensor device [4]. In the case of high power laser applications in hostile

\footnotetext{
${ }^{*}$ Corresponding author. Tel.: +55-44 261 4330; fax: +55-44 2634242.

E-mail address: mlbaesso@dfi.uem.br (M.L. Baesso).
}

environments, restricting limitations are usually imposed on the glass host material to be used [5,6]. The hosts should have high thermal conductivity, high glass transformation temperatures $\left(T_{\mathrm{g}}\right)$, good thermal shock resistance, good chemical durability, high fluorescence quantum efficiency and low phonon energies. Amongst the several glass systems, low silica content calcium aluminosilicate glasses have been shown to fulfill most of these restricting requirements [7-11], besides being nontoxic that is important for surgical laser applications [12].

Despite such properties, only recently to our knowledge, RE doped low silica calcium aluminosilicate glasses attracted the attention of several investigators $[1,10,13-20]$, probably due to the tendency of these glasses towards devitrification, since they are formed with non-network formers $\mathrm{CaO}$ and $\mathrm{Al}_{2} \mathrm{O}_{3}[9]$. The addition of small amounts of alkali and alkaline earth elements enlarges the 
glass forming region, and samples of about $5.5 \mathrm{~kg}$ can be produced [21]. Several calcium aluminate glasses compositions containing silica, magnesium and barium oxide have been investigated by Davy [7] and optimized glass compositions are now reported in the literature [22-27]. Nevertheless, few papers to our knowledge have been devoted to the investigation of low silica calcium aluminosilicate glasses doped with RE ions. And even so most of them were concerned with the investigation of spectroscopic properties such as quantum efficiency, energy transfer process, mechanism of up-conversion [1,10,11,13-18,20]. So, little information is available about the affect of RE doping on their optical, thermal and mechanical properties.

In this work we investigate the affect of RE doping of low silica content calcium aluminosilicate glasses on their mass density $(\rho)$, Vickers microhardness $\left(H_{\mathrm{v}}\right)$, optical absorption coefficient $(\alpha)$, refractive index, glass transition temperature $\left(T_{\mathrm{g}}\right)$ and glass crystallization onset temperature $\left(T_{\mathrm{x}}\right)$.

\section{Experimental}

The low silica calcium aluminosilicate glass samples were prepared from reagent grade powder $\mathrm{CaCO}_{3}(99 \%), \mathrm{Al}_{2} \mathrm{O}_{3}(99.1 \%), \mathrm{SiO}_{2}(99 \%), \mathrm{MgO}$ (97\%), $\mathrm{Er}_{2} \mathrm{O}_{3}(99.99 \%)$ and $\mathrm{Yb}_{2} \mathrm{O}_{3}(99.99 \%)$. The sample compositions are listed in Table 1. A batch was melted at $1470^{\circ} \mathrm{C}$ in $30 \mathrm{~g}$ quantities under vacuum conditions $\left(10^{-3}\right.$ bar $)$ in a graphite crucible for $2 \mathrm{~h}$ for fining. The liquid was cooled by switching off the heater and then moving the crucible upward in the vacuum chamber to a region at room temperature. The sample annealing was carried out at a heating rate of $10^{\circ} \mathrm{Cl}$ min to a few degrees $<T_{\mathrm{g}}$, the glass transition temperature, and remained at this temperature for $12 \mathrm{~h}$, before cooling to room temperature. All glasses were examined for crystallinity with optical microscopy and X-ray diffraction. The samples were cut with a slow speed saw in two different shapes. $3 \mathrm{~mm} \times 3 \mathrm{~mm} \times 10 \mathrm{~mm}$ for optical and mechanical measurements and samples approximately $150 \mathrm{mg}$ for differential thermal analyses (DTA).
The refractive index measurements were performed using a Pulfrich refractometer (JENA DDR) at six different wavelengths: mercury $H$ band $(404.7 \mathrm{~nm})$, mercury $g$ band $(435.8 \mathrm{~nm})$, hydrogen $F$ band (486.1 nm), mercury $e$ band (546.7 $\mathrm{nm})$, helium $d$ band $(587.6 \mathrm{~nm})$ and hydrogen $C$ band $(656.3 \mathrm{~nm})$. The density measurements were carried out using the Archimeds buoyancy method with $\mathrm{CCl}_{4}$ (density $1.594 \mathrm{~g} / \mathrm{cm}^{3}$ at $20^{\circ} \mathrm{C}$ ) as the immersion liquid. Vickers micro-hardness were performed using a micro-hardness tester (Leitz Wetzlar) with $200 \mathrm{~g}$ load during $15 \mathrm{~s}$. To minimize experimental errors, at least 15 indentations were recorded. DTA analysis was performed using an equipment (Netzsch, STA $409-\mathrm{EP}$ ), at a heating rate of $10^{\circ} \mathrm{C} / \mathrm{min}$ until $1400^{\circ} \mathrm{C}$, in an alumina crucible. Optical absorption spectra were recorded on a spectrophotometer (Perkin-Elmer Lambda 9) at room temperature.

\section{Results}

For the doped glasses the limit of vitrification was found at a maximum of $\sim 1.5 \mathrm{~mol} \%$ of RE oxide. In the samples so obtained, observed by optical microscopy, we detected no bubbles striae, as well as no evidence of crystallization in the $\mathrm{X}$ ray diffractograms. The optical absorption spectra of a $\mathrm{Yb}^{3+}$ and $\mathrm{Er}^{3+}$ doped sample are shown in Figs. 1(A)-(C), in which the assignment of the typical $\mathrm{Er}^{3+}$ and $\mathrm{Yb}^{3+}$ transition [28] are indicated. Density $(\rho)$, Vickers micro-hardness $\left(H_{\mathrm{v}}\right)$, glass transition temperature $\left(T_{\mathrm{g}}\right)$, glass crystallization onset temperature $\left(T_{\mathrm{x}}\right)$, mean molecular mass $\bar{M}$ calculated from the relation $\bar{M}=\sum_{i} x_{i} M_{i}$, where $x_{i}$ is the mole fraction of the glass constituents and $M_{i}$ is the molecular mass of the glass constituents and the molar volume, $\bar{V}=\bar{M} / \rho$, are summarized in Table 1. The affect of composition on the density is shown in Fig. 2. The density increased linearly as the RE oxide replaced alumina, from $2.928 \pm 0.005 \mathrm{~g} / \mathrm{cm}^{3}$ for undoped sample to $3.123 \pm 0.005$ for the $1.48 \pm 0.05 \mathrm{~mol}^{\%} \mathrm{Er}_{2} \mathrm{O}_{3}$ doped one. The refractive index $\left( \pm 2 \times 10^{-5}\right)$ as function of RE oxide concentration and wavelength are shown in Figs. 3(A) and (B), respectively. The refractive index increased linearly as 
Table 1

Composition and properties of low silica content calcium aluminosilicate glasses

\begin{tabular}{|c|c|c|c|c|c|c|c|c|c|c|c|c|}
\hline \multirow[t]{2}{*}{ Sample } & \multicolumn{6}{|c|}{ Composition $\left(\mathrm{mol}^{\%} \%\right)$} & \multirow{2}{*}{$\begin{array}{l}\rho \\
\left(\mathrm{g} / \mathrm{cm}^{3}\right) \\
\pm 0.002\end{array}$} & \multirow{2}{*}{$\begin{array}{l}\bar{M} \\
(\mathrm{~g} / \mathrm{mol}) \\
\pm 0.05\end{array}$} & \multirow{2}{*}{$\begin{array}{l}\bar{V} \\
(\mathrm{~mol} / \mathrm{cm}) \\
\pm 0.05\end{array}$} & \multirow{2}{*}{$\begin{array}{l}H_{\mathrm{v}} \\
\left(\mathrm{kg} / \mathrm{mm}^{2}\right)\end{array}$} & \multirow{2}{*}{$\begin{array}{l}T_{\mathrm{g}} \\
\left({ }^{\circ} \mathrm{C}\right) \\
\pm 3 \\
\end{array}$} & \multirow{2}{*}{$\begin{array}{l}T_{\mathrm{x}} \\
\left({ }^{\circ} \mathrm{C}\right) \\
\pm 3 \\
\end{array}$} \\
\hline & $\mathrm{CaO}$ & $\mathrm{Al}_{2} \mathrm{O}_{3}$ & $\mathrm{MgO}$ & $\mathrm{SiO}_{2}$ & $\mathrm{Er}_{2} \mathrm{O}_{3}$ & $\mathrm{Yb}_{2} \mathrm{O}_{3}$ & & & & & & \\
\hline CASM & 58.11 & 27.11 & 6.89 & 7.89 & - & - & 2.928 & 67.75 & 23.14 & $865 \pm 25$ & 841 & 1058 \\
\hline CAYB1 & 57.77 & 27.15 & 6.95 & 7.96 & - & 0.17 & 2.960 & 68.33 & 23.08 & $837 \pm 18$ & 813 & 1029 \\
\hline CAYB3 & 58.35 & 26.06 & 7.02 & 8.04 & - & 0.53 & 3.007 & 69.04 & 22.96 & $814 \pm 29$ & 803 & 993 \\
\hline CAYB5 & 58.94 & 24.97 & 7.09 & 8.12 & - & 0.88 & 3.057 & 69.63 & 22.78 & $807 \pm 24$ & 788 & 982 \\
\hline CAER05 & 59.33 & 27.72 & 4.75 & 8.25 & 0.09 & - & 2.946 & 68.75 & 23.34 & $852 \pm 21$ & 821 & 1038 \\
\hline CAER1 & 57.94 & 26.99 & 6.94 & 7.95 & 0.18 & - & 2.957 & 68.27 & 23.09 & $831 \pm 23$ & 817 & 1035 \\
\hline CAER2 & 57.83 & 26.94 & 6.83 & 8.03 & 0.37 & - & 2.973 & 69.93 & 23.52 & $824 \pm 19$ & 822 & 1018 \\
\hline CAER4 & 58.69 & 25.54 & 6.94 & 8.10 & 0.73 & - & 3.027 & 69.50 & 22.96 & $815 \pm 15$ & 798 & 1000 \\
\hline CAER6 & 59.30 & 24.42 & 7.01 & 8.18 & 1.00 & - & 3.076 & 70.02 & 22.76 & $800 \pm 20$ & 791 & 979 \\
\hline CAER7 & 59.54 & 23.84 & 7.16 & 8.21 & 1.25 & - & 3.099 & 70.30 & 22.68 & $793 \pm 19$ & 787 & 958 \\
\hline CAER 8 & 59.83 & 23.26 & 7.20 & 8.24 & 1.48 & - & 3.123 & 70.95 & 22.72 & $781 \pm 23$ & 782 & 955 \\
\hline CAER2YB3 & 58.93 & 24.96 & 7.09 & 8.12 & 0.37 & 0.53 & 3.053 & 69.74 & 22.94 & $785 \pm 10$ & 794 & 979 \\
\hline CAER2YB4 & 59.23 & 24.40 & 7.13 & 8.16 & 0.37 & 0.71 & 3.075 & 70.08 & 22.79 & $776 \pm 22$ & 790 & 976 \\
\hline CAYB2ER05 & 58.20 & 26.34 & 7.00 & 8.02 & 0.09 & 0.35 & 2.992 & 68.86 & 23.01 & $815 \pm 14$ & 807 & 1006 \\
\hline CAYB2ER1 & 58.34 & 26.06 & 7.03 & 8.04 & 0.18 & 0.35 & 3.002 & 69.02 & 22.99 & $811 \pm 14$ & 798 & 1006 \\
\hline CAYB2ER2 & 58.63 & 25.52 & 8.08 & 7.06 & 0.36 & 0.35 & 3.027 & 69.15 & 22.84 & $808 \pm 11$ & 792 & 983 \\
\hline CAYB2ER3 & 58.92 & 24.96 & 7.09 & 8.12 & 0.55 & 0.35 & 3.036 & 69.72 & 22.96 & $804 \pm 17$ & 798 & 969 \\
\hline CAYB2ER4 & 59.23 & 24.39 & 7.13 & 8.16 & 0.74 & 0.35 & 3.074 & 70.08 & 22.80 & $798 \pm 10$ & 791 & 972 \\
\hline CAYB2ER5 & 59.53 & 23.81 & 7.17 & 8.21 & 0.93 & 0.35 & 3.099 & 70.42 & 22.72 & $795 \pm 13$ & 785 & 969 \\
\hline
\end{tabular}

$\mathrm{RE}$ oxide replaced alumina. The refractive index decreased with increasing wavelength. In Table 2, the refractive index as function of wavelength, average dispersion, $n_{F}-n_{C}$, Abbe number, $v_{d}=$ $\left(n_{d}-1\right) /\left(n_{F}-n_{C}\right)$, and molar refraction are summarized for the samples.

The molar refraction was calculated using Lorentz-Lorenz equation [29]

$M R_{g}=\frac{n^{2}-1}{n^{2}+2} \frac{\bar{M}}{\rho}$,

where $n=n_{d}$ is the refractive index. It follows from Table 2 that $M R_{g}$ remained approximately constant at 8.6. The dependence $H_{\mathrm{v}}$ on the RE oxide doping was such that $H_{\mathrm{v}}$ decreased as $\mathrm{Al}_{2} \mathrm{O}_{3}$ was replaced by the RE oxide, as shown in Fig. 4. Furthermore, this change in $H_{\mathrm{v}}$ is independent of the RE doping, which we suggest is due to the alumina which we assume has the largest affect on $H_{\mathrm{v}}$. Fig. 5 shows the DTA curves for four samples, namely, undoped, $0.09 \mathrm{~mol} \%, 0.73 \mathrm{~mol} \%, 1.48$ $\mathrm{mol} \% \mathrm{Er}_{2} \mathrm{O}_{3}$ doped samples. Increasing the $\mathrm{RE}$ oxide doping shifts the exothermal peaks and $T_{\mathrm{g}}$ towards smaller temperatures. This shift was observed for all samples. The dependence of $T_{\mathrm{g}}$ and $T_{\mathrm{x}}$ on the RE oxide doping concentration are shown in Fig. 6, which shows that both $T_{\mathrm{g}}$ and $T_{\mathrm{x}}$ decrease as the RE oxide doping concentration increases. Finally, Figs. 7(A) and (B) show the dependence of $T_{\mathrm{g}}$ as function of specific volume and of $H_{\mathrm{v}}$ as function of density, respectively. Data for $T_{\mathrm{g}}(1 / \rho)$ and $H_{\mathrm{v}}(\rho)$ can be fit by linear functions with correlation coefficients, $R T_{\mathrm{g}}=0.95$ and $R H_{\mathrm{v}}=0.87$.

\section{Discussion}

It is well-known that RE ions can act either as a network former (as in the case of fluorozirconate glasses) [30] or as a modifier (as in the case of fluoride glasses) [31,32].

The above results indicate that the addition of $\mathrm{Er}, \mathrm{Yb}$ and $\mathrm{Er}-\mathrm{Yb}$ ions in amounts $<1.48 \mathrm{~mol} \%$ to low silica calcium aluminosilicate glasses changes by $<10 \%$ the glass properties. The density increase 



Rare earth Concentration (mol\%)

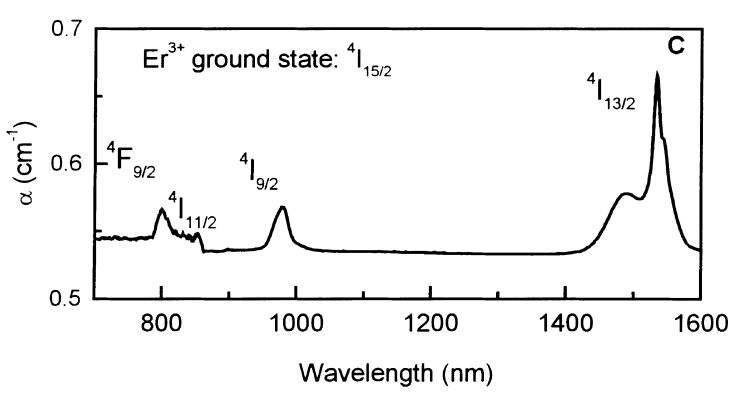

Fig. 1. Visible and IR optical absorption spectra: (A) 0.53 mol\% $\mathrm{Yb}_{2} \mathrm{O}_{3}$ doped sample (2.6 mm); (B) $0.73 \mathrm{~mol}^{\circ} \mathrm{Er}_{2} \mathrm{O}_{3}$ doped sample $(3.0 \mathrm{~mm})$; (C) $0.73 \mathrm{~mol} \% \mathrm{Er}_{2} \mathrm{O}_{3}$ doped sample near infrared.

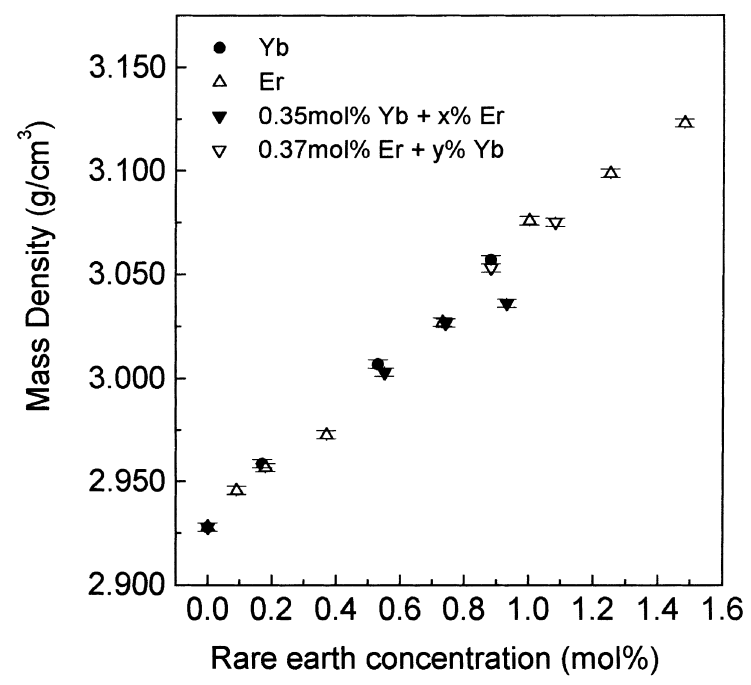

Fig. 2. Mass density as a function of RE oxide concentration.

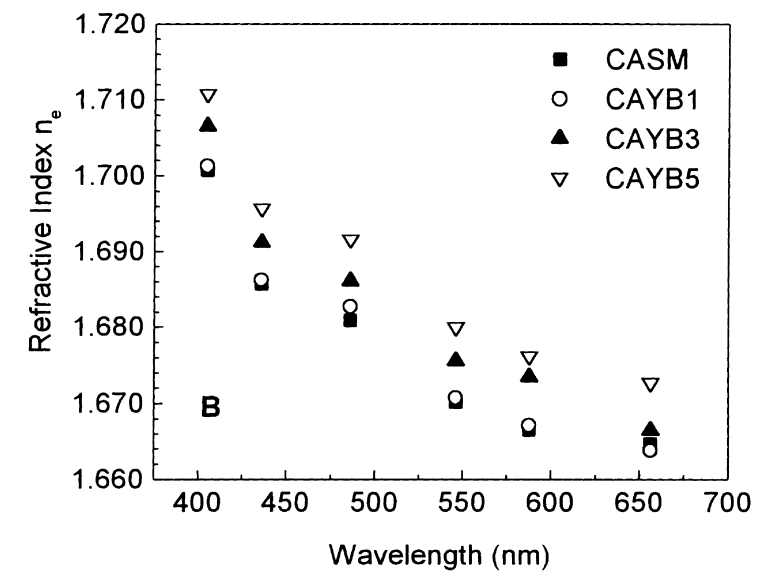

Fig. 3. (A) Refractive index at $546.07 \mathrm{~nm}$ as a function of RE oxide concentration; (B) refractive index as a function of wavelength for $\mathrm{Yb}_{2} \mathrm{O}_{3}$ doped samples.

as a function of $\mathrm{RE}$ oxide concentration is explained by the relative masses of $\mathrm{RE}$ ions in comparison with $\mathrm{Al}$, which it replaces. The increase of the refractive index, between the un-doped sample and the $1.48 \mathrm{~mol}^{\circ} \mathrm{Er}_{2} \mathrm{O}_{3}$ doped sample was of the order of $1 \%$, in accordance with previously reported results $[25,26]$. As discussed in previous works $[25,32]$ the ratio $\mathrm{Al}_{2} \mathrm{O}_{3} / \mathrm{CaO}$ affects the structural properties of these glasses. According to this structural model $[25,32]$ non-bridging oxygen (NBO) occurs when the $\mathrm{Al}_{2} \mathrm{O}_{3} / \mathrm{CaO}$ ratio is less than 1 . In the case of the sample undoped this ratio is 0.466 and 0.388 for $1.48 \mathrm{~mol}^{\%} \mathrm{Er}_{2} \mathrm{O}_{3}$ doped one, i.e., as alumina is replaced by the RE oxide there is a decrease of about $20 \%$ in the 
Table 2

Refractive index dependence of RE doping in low silica calcium aluminosilicate glasses

\begin{tabular}{|c|c|c|c|c|c|c|c|c|c|}
\hline Sample & $\begin{array}{l}H \\
404.7 \mathrm{~nm}\end{array}$ & $\begin{array}{l}g \\
435.8 \mathrm{~nm}\end{array}$ & $\begin{array}{l}F \\
486.1 \mathrm{~nm}\end{array}$ & $\begin{array}{l}e \\
546.07 \mathrm{~nm}\end{array}$ & $\begin{array}{l}d \\
587.6 \mathrm{~nm}\end{array}$ & $\begin{array}{l}C \\
656.3 \mathrm{~nm}\end{array}$ & $\begin{array}{l}n_{F}-n_{C} \\
\left(\times 10^{-3}\right) \\
\pm 0.02\end{array}$ & $\begin{array}{l}v_{d} \\
\pm 0.03\end{array}$ & $\begin{array}{l}M R_{g} \\
\left(\mathrm{~cm}^{3}\right) \\
\pm 0.06\end{array}$ \\
\hline CASM & 1.70073 & 1.68562 & 1.68088 & 1.67015 & 1.66647 & 1.66100 & 19.87 & 33.53 & 8.61 \\
\hline CAYB1 & 1.70121 & 1.68620 & 1.68266 & 1.67075 & 1.66708 & 1.66381 & 18.85 & 35.39 & 8.59 \\
\hline CAYB3 & 1.70647 & 1.69113 & 1.68605 & 1.67545 & 1.67342 & 1.66644 & 19.61 & 34.35 & 8.61 \\
\hline CAYB5 & 1.71071 & 1.69568 & 1.69158 & 1.67992 & 1.67609 & 1.67264 & 18.94 & 35.70 & 8.57 \\
\hline CAER05 & 1.70121 & 1.68586 & 1.68239 & 1.67056 & 1.66673 & 1.66337 & 19.03 & 35.04 & 8.68 \\
\hline CAER 1 & 1.70159 & 1.68639 & 1.68257 & 1.67093 & 1.66732 & 1.66399 & 18.58 & 35.92 & 8.60 \\
\hline CAER2 & 1.70258 & 1.68739 & 1.68302 & 1.67375 & 1.66838 & 1.66455 & 18.46 & 36.20 & 8.77 \\
\hline CAER4 & 1.70763 & 1.69248 & 1.68797 & 1.67829 & 1.67458 & 1.66761 & 20.36 & 33.14 & 8.62 \\
\hline CAER6 & 1.71203 & 1.69679 & 1.69292 & 1.68264 & 1.67669 & 1.67327 & 19.65 & 34.43 & 8.57 \\
\hline CAER7 & 1.71573 & 1.70047 & 1.69506 & 1.68422 & 1.68225 & 1.67518 & 19.88 & 34.33 & 8.59 \\
\hline CAER 8 & 1.71900 & 1.70396 & 1.69720 & 1.68763 & 1.68398 & 1.67689 & 20.30 & 33.69 & 8.62 \\
\hline CAER2YB3 & 1.71090 & 1.69582 & 1.69167 & 1.67996 & 1.67587 & 1.67242 & 19.25 & 35.11 & 8.59 \\
\hline CAER2YB4 & 1.71099 & 1.69564 & 1.69274 & 1.68018 & 1.67676 & 1.67322 & 19.52 & 34.67 & 8.58 \\
\hline CAYB2ER05 & 1.70601 & 1.69094 & 1.68471 & 1.67523 & 1.67293 & 1.66589 & 18.82 & 35.75 & 8.63 \\
\hline CAYB2ER1 & 1.70647 & 1.69136 & 1.68578 & 1.67572 & 1.67422 & 1.66716 & 18.62 & 36.20 & 8.63 \\
\hline CAYB2ER2 & 1.71003 & 1.69472 & 1.68708 & 1.67882 & 1.67467 & 1.66769 & 19.38 & 34.81 & 8.58 \\
\hline CAYB2ER3 & 1.71026 & 1.69522 & 1.69194 & 1.67948 & 1.67604 & 1.67255 & 19.38 & 34.88 & 8.64 \\
\hline CAYB2ER4 & 1.71231 & 1.69702 & 1.69292 & 1.68277 & 1.67732 & 1.67377 & 19.14 & 35.38 & 8.59 \\
\hline CAYB2ER5 & 1.71591 & 1.70070 & 1.69515 & 1.68444 & 1.68222 & 1.67518 & 19.96 & 34.17 & 8.61 \\
\hline
\end{tabular}

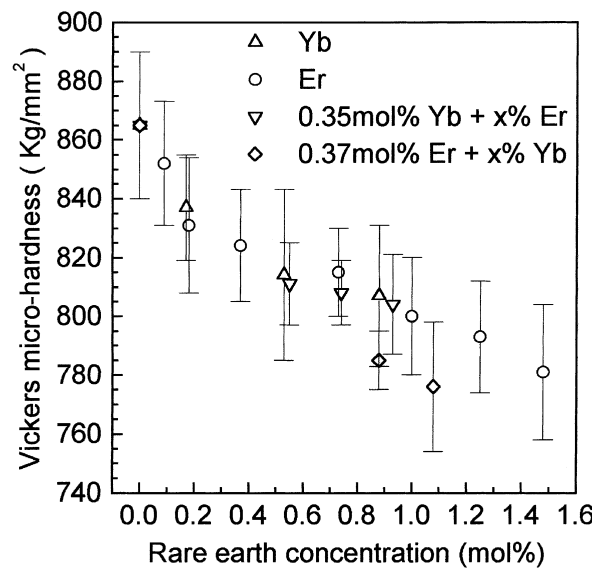

Fig. 4. Vickers micro-hardness for different RE oxide concentration.

$\mathrm{Al}_{2} \mathrm{O}_{3} / \mathrm{CaO}$ ratio. As a consequence there is an increase of the NBO in the samples, which, in turn, entails an increase of their polarizability. As a result of this increase in polarizability the refractive index should also increase [33].

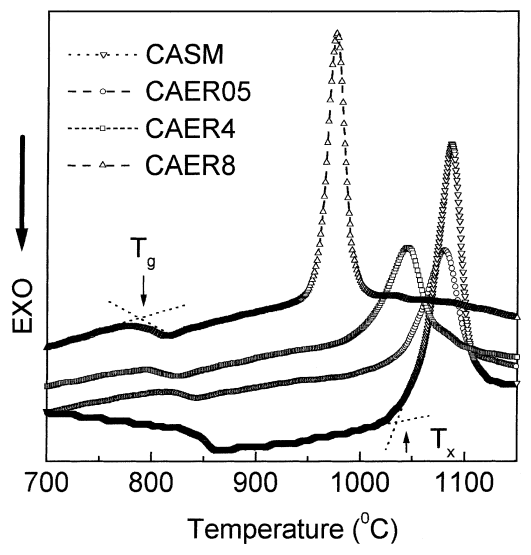

Fig. 5. DTA curves showing the shift of thermal events $\left(T_{\mathrm{g}}\right.$ and $T_{\mathrm{x}}$ ) towards smaller temperatures.

The decrease of $H_{\mathrm{v}}$ was of the order of $10 \%$. This decrease is explained assuming that the RE ions disrupt the tetrahedral network, thereby decreasing the network connectivity. We explain the decrease of $T_{\mathrm{g}}$ by about $59^{\circ} \mathrm{C}$ in the $1.48 \mathrm{~mol} \%$ $\mathrm{Er}_{2} \mathrm{O}_{3}$ doped one by assuming that the RE-O 


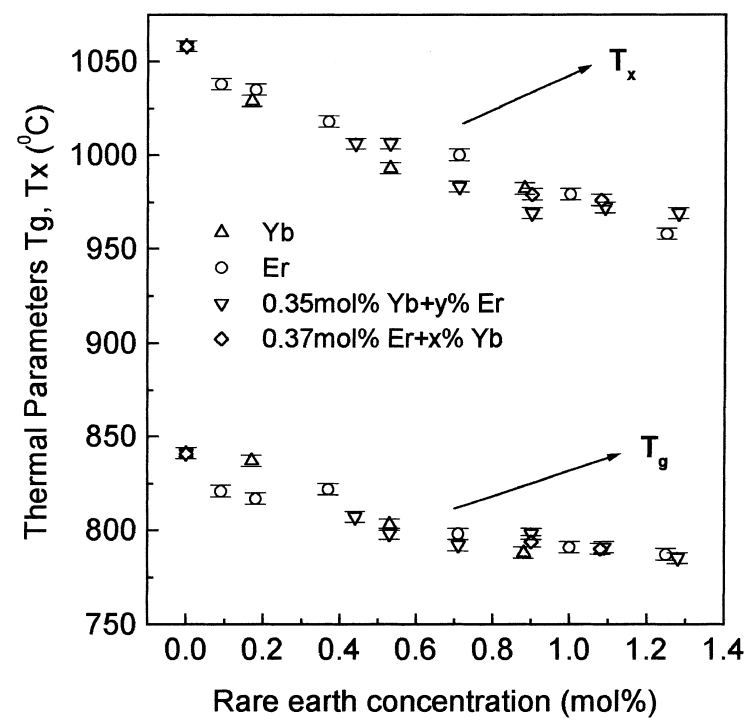

Fig. 6. Thermal parameters $T_{\mathrm{x}}$ and $T_{\mathrm{g}}$ as $\mathrm{Al}_{2} \mathrm{O}_{3}$ is replaced by RE oxide.

bonds are weaker than aluminum-oxygen bonds. As discussed by Shelby and Slilaty [25] the replacement of $\mathrm{Al}_{2} \mathrm{O}_{3}$ by $\mathrm{Ga}_{2} \mathrm{O}_{3}$ causes a decrease of $T_{\mathrm{g}}$ based on smaller strength of $\mathrm{Ga}_{2} \mathrm{O}_{3}$ bonding compared to $\mathrm{Al}_{2} \mathrm{O}_{3}$. As $\mathrm{RE}$ cations have smaller field strength as compared to $\mathrm{Al}$, we assume that the connectivity of the glass structure decreases, requiring less thermal energy for the movement of the less connected structural units and decreasing viscosity. Although the temperature range, between $T_{\mathrm{x}}$ and $T_{\mathrm{g}}$ (in which the case of our samples is around $190^{\circ} \mathrm{C}$ ), as discussed in previous works [27,32], this parameter is not entirely reliable for predicting glass stability, since the sample compositions investigated are in the range close to a phase diagram limit. Finally, from linear fitting $T_{\mathrm{g}}(1 / \rho)$ and $H_{\mathrm{v}}(\rho)$ we conclude that the changes in the glass network induced by RE doping affects $H_{\mathrm{v}}$ and $T_{\mathrm{g}}$ in a similar manner.

\section{Conclusion}

The results showed that these glasses allowed the inclusion of a considerable amount of RE oxide $(<2.0 \mathrm{~mol} \%)$ without devitrification and had only small changes in properties such as mass
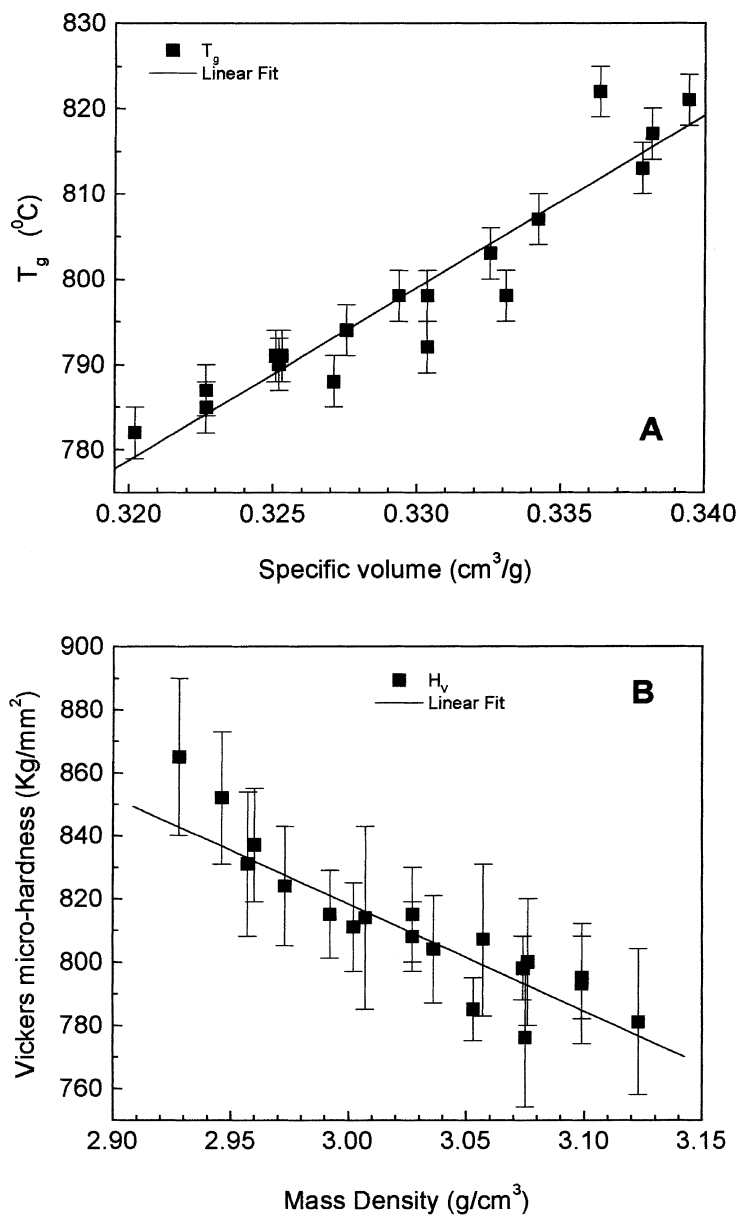

Fig. 7. (A) $T_{\mathrm{g}}$ as a function of specific volume; (B) Vickers micro-hardness as a function of mass density. Solid curve represents linear regression.

density, refractive index, micro-hardness and $T_{\mathrm{g}}$. There was an increase of density by approximately $7 \%$, and refractive index of the order of $1 \%$. In contrast, the Vickers micro-hardness and $T_{\mathrm{g}}$ decreased approximately $9 \%$ and $7 \%$, respectively, from undoped to the $1.48 \mathrm{~mol} \% \mathrm{Er}_{2} \mathrm{O}_{3}$ doped sample. Based on our results we suggest that $\mathrm{RE}^{3+}$ ion act as modifiers in the structure of the low silica calcium aluminosilicate glasses investigated in this work. Since the changes in the main physical properties of these glasses was $<10 \%$, we suggest they should be considered as candidates for active media in the development of glass lasers. 


\section{Acknowledgements}

We are thankful to Brazilian Agencies: Capes, $\mathrm{CNPq}$ and FAPESP for the financial support of this work.

\section{References}

[1] D.F. de Souza, L.F.C. Zonetti, M.J.V. Bell, J.A. Sampaio, L.A.O. Nunes, M.L. Baesso, A.C. Bento, L.C.M. Miranda, Appl. Phys. Lett. 74 (1999) 908.

[2] F.E. Auzel, Proc. IEEE 61 (1973) 758.

[3] R.M. Dwyer, M. Bass, in: M. Ross (Ed.), Lasers in Medicine, vol. 3, Academic Press, New York, 1977, p. 107.

[4] K. Kincade, Laser Focus World (1996) 73.

[5] N. Neuroth, Opt. Eng. 26 (1987) 96.

[6] M.J. Weber, J. Non-Cryst. Solids 123 (1990) 208.

[7] J.R. Davy, Glass Technol. 19 (1978) 32.

[8] G.Y. Onoda Jr., S.D. Brown, J. Am. Ceram. Soc. 53 (1970) 311.

[9] J.E. Shelby, J. Am. Ceram. Soc. 68 (1985) 155.

[10] M.L. Baesso, A.C. Bento, A.R. Duarte, A.M. Neto, L.C.M. Miranda, J.A. Sampaio, T. Catunda, S. Gama, F.C.G. Gandra, J. Appl. Phys. 85 (1999) 8112.

[11] S. Tanabe, T. Ohyagi, T. Hanada, N. Soga, J. Ceram. Soc. Jpn. 101 (1993) 74.

[12] T. Abel, J.A. Harrington, P.R. Foy, Appl. Opt. 33 (1994) 3919.

[13] X. Zou, T. Izumitani, J. Non-Cryst. Solids 162 (1993) 68.

[14] X. Zou, T. Izumitani, J. Ceram. Soc. Jpn. 101 (1993) 80.

[15] X. Zou, T. Izumitani, J. Ceram. Soc. Jpn. 101 (1993) 85.

[16] M.L. Baesso, A.C. Bento, A.A. Andrade, T. Catunda, J.A. Sampaio, S. Gama, J. Non-Cryst. Solids 219 (1997) 165.
[17] M.L. Baesso, A.C. Bento, A.A. Andrade, J.A. Sampaio, E. Pecoraro, L.A.O. Nunes, T. Catunda, S. Gama, Phys. Rev. B 57 (1998) 10545.

[18] E.V. Uhlmann, M.C. Weinberg, N.J. Kreidl, L.L. Burgner, R. Zanoni, K.H. Church, J. Non-Cryst. Solids 178 (1994) 15.

[19] J.A. Sampaio, T. Catunda, F.C.G. Gandra, S. Gama, A.C. Bento, L.C.M. Miranda, M.L. Baesso, J. Non-Cryst. Solids 247 (1999) 196.

[20] W.J. Chung, J.R. Yoo, Y.S. Kim, J. Heo, J. Am. Ceram. Soc. 80 (1997) 1485.

[21] H.C. Hafner, N.J. Kreidl, R.A. Weidel, J. Am. Ceram. Soc. 41 (1958) 315.

[22] C. Huang, E.C. Behrman, J. Non-Cryst. Solids 128 (1991) 310.

[23] C. Oprea, D. Togan, C. Popescu, Thermochim. Acta 194 (1992) 165.

[24] E.V. Uhlmann, M.C. Weinberg, N.J. Kreidl, A.A. Goktas, J. Am. Ceram. Soc. 76 (1993) 499.

[25] J.E. Shelby, R.M. Slilaty, J. Appl. Phys. 68 (1990) 3207.

[26] J.E. Shelby, M.M. Wierzbicki, Phys. Chem. Glasses 36 (1995) 17.

[27] P.L. Higby, R.J. Ginther, I.D. Aggarwal, E.J. Friebele, J. Non-Cryst. Solids 126 (1990) 209.

[28] W.T. Carnall, P.R. Fields, K. Rajnak, J. Chem. Phys. 49 (1968) 2212.

[29] W. Vogel, Glass Chemistry, 2nd Ed., Springer, Berlin, 1994, p. 411.

[30] L. Lucas, M. Chasnthanasinh, M. Poulain, P. Brun, M.J. Weber, J. Non-Cryst. Solids 27 (1978) 273.

[31] J.E. Shelby, J.T. Kohli, J. Am. Ceram. Soc. 73 (1990) 39.

[32] J.T. Kohli, J.E. Shelby, Phys. Chem. Glasses 32 (1991) 67.

[33] J.E. Shelby, C.M. Shaw, M.S. Spess, J. Appl. Phys. 66 (1989) 1149. 